\title{
Molecular detection of bovine coronavirus in a diarrhea outbreak in pasture-feeding Nellore steers in southern Brazil
}

\author{
Juliane Ribeiro $^{1} \cdot$ Elis Lorenzetti $^{1}$ - Alice Fernandes Alfieri ${ }^{1}$ - Amauri Alcindo Alfieri ${ }^{1}$
}

Received: 28 April 2015 / Accepted: 8 December 2015 /Published online: 28 December 2015

(C) Springer Science+Business Media Dordrecht 2015

\begin{abstract}
Worldwide diarrhea outbreaks in cattle herds are more frequently detected in calves being that diarrhea outbreaks in adult cattle are not common. Winter dysentery (WD) is a bovine coronavirus (BCoV) enteric infection that is more reported in Northern hemisphere. Seasonal outbreaks of WD in adult cattle occur mainly in dairy cows. WD has not been described in beef cattle herds of tropical countries. This study describes the molecular detection of $\mathrm{BCoV}$ in a diarrhea outbreak in beef cattle steers (Nellore) raised on pasture in Parana, southern Brazil. During the outbreak, the farm had about 600 fattening steers. Watery and bloody diarrhea unresponsive to systemic broad-spectrum antibiotic therapy reveals a morbidity rate of approximately $15 \%$. The $\mathrm{BCoV} \mathrm{N}$ gene was identified in $42.9 \%(6 / 14)$ of the diarrheic fecal samples evaluated by semi-nested polymerase chain reaction (SN-PCR) technique. Other enteric microorganisms occasionally identified in adult cattle and evaluated in this study such as bovine groups $\mathrm{A}, \mathrm{B}$, and $\mathrm{C}$ rotavirus, bovine viral diarrhea virus, bovine torovirus, aichivirus B, and Eimeria sp. were not identified in the fecal samples. To the best knowledge of the authors, this is the first description of the $\mathrm{BCoV}$ diagnosis in fecal samples collected in a diarrhea outbreak in adult beef cattle grazing in the grass in a tropical country.
\end{abstract}

Amauri Alcindo Alfieri

alfieri@uel.br

1 Laboratory of Animal Virology and Multi-User Animal Health Laboratory, Molecular Biology Unit, Department of Veterinary Preventive Medicine, Universidade Estadual de Londrina, Rodovia Celso Garcia Cid-Campus Universitário, PO Box 10011, CEP 86057-970 Londrina, Parana, Brazil
Keywords Beef cattle $\cdot$ Diarrhea $\cdot \mathrm{BCoV} \cdot$ Extensive management

\section{Introduction}

The bovine coronavirus $(\mathrm{BCoV})$ is a RNA virus that belongs to the Betacoronavirus 1 species in the Betacoronavirus genus of the Coronaviridae family. The $\mathrm{BCoV}$ is a RNA virus, nonenveloped, diameter of $120 \mathrm{~nm}$, single-stranded (ssRNA) positive-sense, and non-segmented with $27-32 \mathrm{~Kb}$ size (ICTV 2015).

The genome of the coronavirus consists of five structural proteins; nucleocapsid $(\mathrm{N})$, transmembrane $(\mathrm{M})$, hemagglutinin esterase (HE), spike (S), and small membrane (E) proteins. The $\mathrm{S}$ protein comprises two subunits ( $\mathrm{S} 1$ and $\mathrm{S} 2$ ), and shows an important role during the virus-host cell interaction acting in viral pathogenesis. The $\mathrm{N}$ protein is considered best target for detection of genomic RNA to represent the most conserved region among strains and more abundant on infected cells (ICTV 2015).

The $\mathrm{BCoV}$ infections are associated with severe diarrhea in newborn calves (Boileau and Kapil 2010), respiratory infections in calves and feedlot cattle (Fulton et al. 2013), and winter dysentery (WD) in adult cattle (Ko et al. 2006; Natsuaki et al. 2007).

Diarrhea outbreaks in adult cattle are uncommon. The $\mathrm{BCoV}$ was characterized as agent of acute diarrhea outbreaks in dairy cows in the winter season known as WD (Jeong et al. 2005). The infection is characterized by affect mainly dairy cattle displaying dark watery diarrhea, which is accompanied by variable depression and anorexia (Valle et al. 2006). This disease is also marked by high morbidity $(100 \%)$ with spontaneous recovery and rarely death cases are recorded in affected animals (Natsuaki et al. 2007). 
The occurrence of $\mathrm{BCoV}$ infection causing WD in dairy cows has already been reported in countries of Europe (Decaro et al. 2008), Asia (Park et al. 2006; Natsuaki et al. 2007), and America (Valle et al. 2006; Takiuchi et al. 2009).

The $\mathrm{BCoV}$ is more stable in cold temperatures favoring viral spread in the herd (Takiuchi et al. 2009). The WD is described mainly in winter in the Northern hemisphere countries (Decaro et al. 2008; Boileau and Kapil 2010). However, this disease has already been reported in dairy cattle herds in warmer seasons (Park et al. 2006) and in tropical country (Takiuchi et al. 2009).

The diarrhea in adult bovine may also be occasionally caused by other enteric viral agents such as bovine rotavirus groups A (BoRVA) (Masuda et al. 2014), B (BoRVB) (Chang et al. 1997), and C (BoRVC) (Mawatari et al. 2004), bovine torovirus (BToV) (Ito et al. 2007), aichivirus B (Ribeiro et al. 2014), and bovine viral diarrhea virus (BVDV) (Lunardi et al. 2008).

The diarrhea is considered a multifactorial and multietiologic syndrome (Takiuchi et al. 2006). Although, the production of beef cattle created extensively in Brazil has received improvements in breeding techniques. Practices to prevent and control diseases should be based on good practices of creation of the animals (vaccination, deworming, water, and good quality pasture), herd size, presence of pathogens, and environmental factors (Cho and Yoon 2014).

Around the world, there are no reports of diarrhea outbreaks caused by $\mathrm{BCoV}$ affecting adult beef cattle in extensive management in a tropical country. The present study reports a diarrhea outbreak in a beef cattle grazing in the grass in a Brazilian herd.

\section{Materials and methods}

\section{Steers management}

The farm contains 600 Nellore breed steers created in an extensive management (pasture feeding), located in northern of the Parana state $\left(23^{\circ} 17^{\prime} 34^{\prime \prime} \mathrm{S}\right.$; $\left.51^{\circ} 10^{\prime} 24^{\prime \prime} \mathrm{W}\right)$, in southern Brazil. The steers are routinely vaccinated against foot and mouth disease and clostridiosis; received regular treatment against endo- and ectoparasites, maintained predominantly on green pastures with predominant Brachiaria brizantha, and supplemented with commercial mineral salt (protein salt during winter). The good quality water was given ad libitum.

\section{Fecal samples}

During June of 2013 occurred a diarrhea outbreak in this herd affecting $15 \%$ of the steers with watery and bloody diarrhea with 5 days of duration of the clinic signs.
The animals had between 24 and 36 months old and demonstrated clinical signs of enteric disorders associated with weight loss, besides depression, anorexia, and diarrhea aqueous dark of sudden onset in which four diarrheic steers died.

Preliminary exams performed with 10 fecal samples for the diagnosis of Eimeria sp. by flotation technique and examined microscopically using $400 \times$ showed that all diarrheic fecal samples evaluated to coccidiosis were negative (data not shown).

The steers showing clinical signs of diarrhea were unresponsive to systemic and oral broad-spectrum antibiotic therapy (oxytetracycline). Therefore, the virological diagnosis was conducted by collecting 14 fecal samples from steers with clinical signs of diarrhea. The samples were transported at $4{ }^{\circ} \mathrm{C}$ and stored at $-80^{\circ} \mathrm{C}$ until processing.

\section{Nucleic acid extraction}

Fecal suspensions were prepared at 10-20\%(w/v) with $0.01 \mathrm{M}$ phosphate-buffered (PBS) pH $7.2(137 \mathrm{mM} \mathrm{NaCl}$; $3 \mathrm{mM} \mathrm{KCl} ; 8 \mathrm{mM} \mathrm{Na} 2 \mathrm{HPO}_{4} ; 14 \mathrm{mM} \mathrm{KH}_{2} \mathrm{PO}_{4}$ ) and centrifuged at $3000 \times \mathrm{g}$ for $5 \mathrm{~min}$. Aliquots of $400 \mu \mathrm{l}$ of supernatant were treated with SDS ( $1 \%$ final concentration) and incubated for $30 \mathrm{~min}$ at $56{ }^{\circ} \mathrm{C}$. The nucleic acid extraction was realized using a combination of phenol/chloroform/isoamyl alcohol (25:24:1) and silica/guanidinium isothiocyanate methods (Alfieri et al. 2006). The nucleic acid was eluted in $50 \mu \mathrm{l}$ of ultrapure RNase-free diethylpyrocarbonate (DEPC)-treated sterile water. Negative control (sterile water) was included in all nucleic acid extraction procedures.

\section{Virological analysis}

The RNA of enteric viruses in the diarrheic fecal samples was investigated by molecular techniques (RT-PCR and SN-PCR) for amplification of $251 \mathrm{bp}$ length of BCoV N gene (Takiuchi et al. 2006); 876 bp and 1062 bp of BoRVA VP4 and VP7 genes, respectively (Gouvea et al. 1990; Gentsch et al. 1992); 434 bp of BoRVB NSP2 gene (Gouvea et al. 1991); 270 bp of BoRVC VP6 gene (Alfieri et al. 1999); 471 bp of BToV N gene (Ito et al. 2007); 216 bp of aichivirus B RdRp gene (Reuter et al. 2009); and 288 bp of BVDV 5'UTR region gene (Vilcek et al. 1994).

The RT-PCR and SN-PCR products were analyzed by electrophoresis in a $2 \%$ agarose gel in TBE buffer $\mathrm{pH} 8.4(89 \mathrm{mM}$ Tris; $89 \mathrm{mM}$ boric acid; $2 \mathrm{mM}$ EDTA), stained with ethidium bromide $(0.5 \mu \mathrm{g} / \mathrm{ml})$, and visualized under UV light.

\section{Sequencing analysis}

The presence of the $\mathrm{BCoV}$ in the diarrheic fecal samples was confirmed by sequencing. Two SN-PCR products with better quality were purified using the GFX PCR DNA and Gel Band 
Purification Kit (GE Healthcare, Little Chalfont, UK), quantified in a Qubit ${ }^{\circledR}$ Fluorometer (Invitrogen Life Technologies, Eugene, OR, USA), and sequenced in an ABI3500 Genetic Analyzer sequencer with the BigDye ${ }^{\circledR}$ Terminator v3.1 Cycle Sequencing Kit using the forward and reverse primers used in the SN-PCR assay (Applied Biosystems, Foster City, CA, USA). Sequence quality analysis was performed using Phred software and the consensus sequences were assembled using the CAP3 software (http://asparagin.cenargen.embrapa.br/ $\mathrm{phph} /$ ). Sequence similarity searches were performed using the basic local alignment search tool (BLAST) software (http://blast.ncbi.nlm.nih.gov/), to verify the nucleotide similarity with sequences that are deposited in public databases. The phylogenetic tree and the nucleotide identity matrix were realized using the MEGA version 5.10 and Bioedit version 7.1.3.0 software, respectively. The analyses were based on the maximum-likelihood method from the Jukes-Cantor model. Bootstrapping was statistically supported with 1000 replicates. The referenced sequences included in this study were acquired from the National Center for Biotechnology Information, USA (GenBank) (http://www. ncbi.nlm.nih.gov/GenBank/).

\section{Results and discussion}

Diarrhea outbreaks affecting animals rearing in pasture frequently are not reported. In this study, the cattle farm had good nutritional and health management; however, several steers negative for coccidial infections and unresponsive to broadspectrum antibiotic therapy showed diarrhea simultaneously. Therefore, we used the techniques of RT-PCR and SN-PCR that have high specificity and sensitivity to detect the main agents that may be involved in enteric outbreaks of adult cattle.

Amplicons of 251 bp length were amplified by SN-PCR performed for $\mathrm{BCoV}$ diagnosis in $6(42.85 \%)$ of the 14 diarrheic fecal samples included in this study. The SN-PCR amplified products were confirmed as $\mathrm{BCoV} \mathrm{N}$ gene by nucleotide (nt) sequence analysis. Two nt sequences of better quality selected for phylogenetic analysis exhibited $100 \%$ of nt identity with each other, $98.1 \%$ with other Brazilian BCoV strains (FJ603611 to FJ603613) that were described in a diarrhea outbreak in calves (Stipp et al. 2009), and $100 \%$ with strains related in enteric problems in dairy cows (KJ719308 to KJ719309) (Fig. 1).

Around the world, other viruses have also been described in smaller frequency in cases of diarrhea in adult animals highlighting BoRVA (Masuda et al. 2014), BoRVB (Chang et al. 1997), BoRVC (Mawatari et al. 2004), aichivirus B (Ribeiro et al. 2014), BVDV (Lunardi et al. 2008), and BToV (Ito et al. 2007). In order to assess the type of enteric (single or mixed) infection, these potentially pathogenic viral agents already described in diarrheic fecal samples of adult cattle were included in the differential diagnosis. However, all diarrheic fecal samples analyzed were negative for these six virus evaluated.

The Brazil shows a tropical weather revealing not defined seasons. During the month of June/2013, period of diarrhea outbreak, the Parana state registered maximum temperatures of $22{ }^{\circ} \mathrm{C}$ and a minimum of $10^{\circ} \mathrm{C}$. Cold weather and low air relative humidity facilitate the $\mathrm{BCoV}$ spread in the environment (Takiuchi et al. 2009)

In a cattle herd, some steers can be with $\mathrm{BCoV}$ subclinical infections and are asymptomatic carriers of the virus. For cattle raised on pasture, weather conditions that lead to rapid thermal inversion are certainly a cause of great stress for the animals. Based on the maximum and minimum temperatures registered in Parana state during the period of the outbreak, we believe that thermal stress may have caused the virus circulation in the herd causing the enteric infection and the diarrhea outbreak.

Diarrhea outbreaks involving the BCoV usually not cause death of animals. Even not having the opportunity to perform
Fig. 1 Phylogenetic analysis of a partial nucleotide sequence (nt 218) of the $\mathrm{N}$ gene of $\mathrm{BCoV}$. The tree was generated using the maximum-likelihood method from the Jukes-Cantor as the nucleotide substitution model. Bootstraps values (1000 replicates). The Brazilian $\mathrm{BCoV}$ strains described in this study are marked with a filled circle. Canine coronavirus strain was used as outgroup

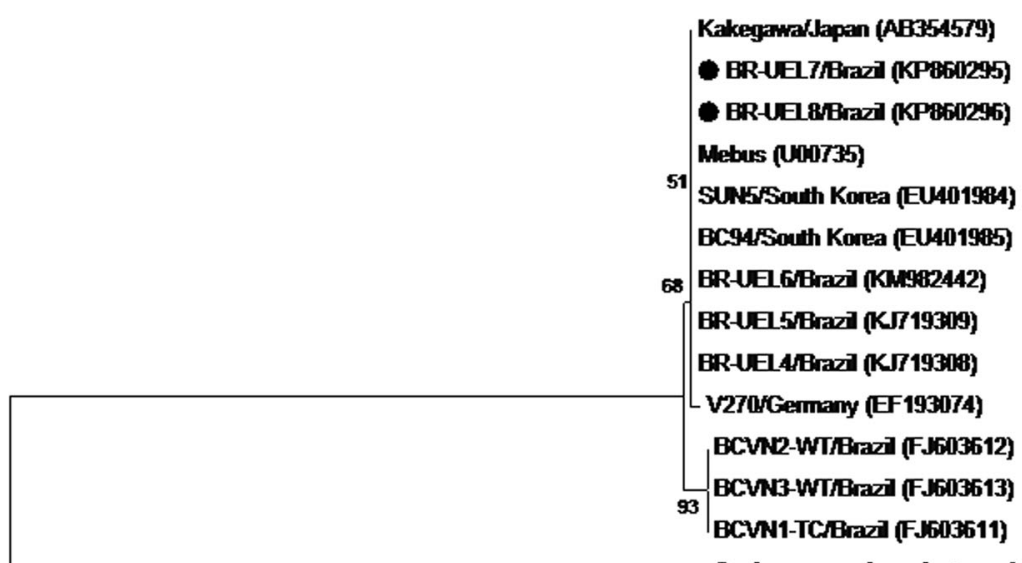

Canine coronenius giant panda strainfChina (AY436635) 
necropsy, all the information regarding the epidemiology, treatment, and the range of negatives etiologic diagnoses suggest that this outbreak can be classified as uncommon because the death of four diarrheic steers occurred.

The $\mathrm{BCoV}$ is an important infectious agent that must be investigated in cases of enteric disorders in adult animals (Jeong et al. 2005; Natsuaki et al. 2007). However, this infection is more frequently reported in cows of dairy farms (Decaro et al. 2008; Takiuchi et al. 2009). This study demonstrated that the presence of $\mathrm{BCoV}$ in diarrhea outbreak in pasture-feeding Nellore steers was caused by $\mathrm{BCoV}$ infection. This is the first description of adult diarrhea outbreak in a beef cattle herd in a tropical country demonstrating the importance of the $\mathrm{BCoV}$ diagnosis in diarrhea outbreak in adult beef cattle in extensive management.

Usually, the diarrhea outbreaks related to extensive breeding herds are not investigated. However, with improvements in animal breeding techniques, it is important to research all pathogens that affect livestock. In situations of clinical cases occurrence characterized with sporadic diarrhea, the laboratory diagnosis is rarely realized and is difficult to identify the etiological agent involved. Thus, frequently, the result obtained is not conclusive or rarely exhibited.

This study allowed to identify for the first time that the $\mathrm{BCoV}$ is a potential cause of diarrhea in pasture-feeding Nellore steers in a tropical country. With that, the results showed the importance of the inclusion of $\mathrm{BCoV}$ in the diagnosis of diarrhea outbreaks in adult cattle regardless the type of herd (dairy or beef), management (intensive or extensive), and season (winter or summer).

Acknowledgments This study was supported by the following Brazilian institutes: National Council of Scientific and Technological Development (CNPq), Brazilian Federal Agency for Support and Evaluation of Graduate Education (CAPES), Financing of Studies and Projects (FINEP), and the Araucaria Foundation (FAP/PR). Alfieri, A.A., Alfieri, A.F., and Lorenzetti, E. are recipients of CNPq fellowships.

\section{Compliance with ethical standards}

Conflict of interest The authors declare that they have no competing interests.

\section{References}

Alfieri, A.A., Leite, J.P., Alfieri, A.F., Jiang, B., Glass, R.I. and Gentsch, J.R., 1999. Detection of field isolates of human and animal group C rotavirus by reverse transcription-polymerase chain reaction and digoxigenin-labeled oligonucleotide probes, Journal of Virological Methods, 83, 35-43

Alfieri, A.A., Parazzi, M.E., Takiuchi, E., Medici, K.C. and Alfieri, A.F., 2006. Frequency of group A rotavirus in diarrhoeic calves in
Brazilian cattle herds, 1998-2002, Tropical Animal Health and Production, 38, 521-526

Boileau, M.J. and Kapil, S., 2010. Bovine coronavirus associated syndromes, Veterinary Clinics of North America: Food Animal Practice, 26, 123-146

Chang, K.O., Parwani, A.V., Smith, D. and Saif, L.J., 1997. Detection of group B rotaviruses in fecal samples from diarrheic calves and adult cows and characterization of their VP7 genes, Journal of Clinical Microbiology, 35, 2107-2110

Cho, Y.I. and Yoon, K.J., 2014. An overview of calf diarrhea - infectious etiology, diagnosis, and intervention, Research in Veterinary Science, 15, 1-17

Decaro, N., Mari, V., Desario, C., Campolo, M., Elia, G., Martella, V., Greco, G., Cirone, F., Colaianni, M.L., Cordioli, P. and Buonavoglia, C., 2008. Severe outbreak of bovine coronavirus infection in dairy cattle during the warmer season, Veterinary Microbiology, 126, 30-39

Fulton, R.W., Ridpath, J.F. and Burge, L.J., 2013. Bovine coronaviruses from the respiratory tract: antigenic and genetic diversity, Vaccine, $31,886-892$

Gentsch, J.R., Glass, R.I., Woods, P., Gouvea, V., Gorziglia, M., Flores, J., Das, B.K. and Bhan, M.K., 1992. Identification of group A rotavirus gene 4 types by polymerase chain reaction, Journal of Clinical Microbiology, 30, 1365-1373

Gouvea, V., Glass, R.I., Woods, P., Taniguchi, K., Clark, H.F., Forrester, B. and Fang, Z.Y., 1990. Polymerase chain reaction amplification and typing of rotavirus nucleic acid from stool specimens, Journal of Clinical Microbiology, 28, 276-282

Gouvea, V., Allen, J.R., Glass, R.I., Fang, Z.Y., Bremont, M., Cohen, J., McCrae, M.A., Saif, L.J., Sinarachatanant, P. and Caul, E.O., 1991. Detection of group B and C rotaviruses by polymerase chain reaction, Journal of Clinical Microbiology, 29, 519-523

ICTV - International Committee on Taxonomy of Viruses $<\mathrm{http}: / /$ www. ictvonline.org/virusTaxonomy.asp> Accessed in: 03 Jan 2015

Ito, T., Okada, N. and Fukuyama, S., 2007. Epidemiological analysis of bovine torovirus in Japan, Virus Research, 126, 32-37

Jeong, J.H., Kim, G.Y., Yoon, S.S., Park, S.J., Kim, Y.J., Sung, C.M., Jang, O.J., Shin, S.S., Koh, H.B., Lee, B.J., Lee, C.Y., Kang, M.I., Kim, H.J., Park, N.Y. and Cho, K.O., 2005. Detection and isolation of winter dysentery bovine coronavirus circulated in Korea during 2002-2004, The Journal of Veterinary Medical Science, 67, 187-189

Ko, C.K., Kang, M.I., Lim, G.K., Kim, G.Y., Yoon, S.S., Park, J.T., Jeong, C., Park, S.H., Park, S.J., Kim, Y.J., Jeong, J.H., Kim, S.K., Park, S.I., Kim, H.H., Kim, K.Y. and Cho, K.O., 2006. Molecular characterization of $\mathrm{HE}, \mathrm{M}$, and $\mathrm{E}$ genes of winter dysentery bovine coronavirus circulated in Korea during 2002-2003, Virus Genes, 32, $129-136$

Lunardi, M., Headley, S.A., Lisboa, J.A.N., Amude, A.M. and Alfieri, A.A., 2008. Outbreak of acute bovine viral diarrhea in Brazilian beef cattle: Clinicopathological findings and molecular characterization of a wild-type BVDV strain subtype 1b, Research in Veterinary Science, 85, 599-604

Masuda, T., Nagai, M., Yamasato, H., Tsuchiaka, S., Okazaki, S., Katayama, Y., Oba, M., Nishiura, N., Sassa, Y., Omatsu, T., Furuya, T., Koyama, S., Shirai, J., Taniguchi, K., Fujii, Y., Todaka, R., Katayama, K. and Mizutani, T., 2014. Identification of novel bovine group A rotavirus G15P[14] strain from epizootic diarrhea of adult cows by de novo sequencing using a next-generation sequencer, Veterinary Microbiology, 171, 66-73

Mawatari, T., Taneichi, A., Kawagoe, T., Hosokawa, M., Togashi, K. and Tsunemitsu, H., 2004. Detection of a bovine group C rotavirus from adult cows with diarrhea and reduced milk production, The Journal of Veterinary Medical Science, 66, 887-890

Natsuaki, S., Goto, K., Nakamura, K., Yamada, M., Ueo, H., Komori, T., Shirakawa, H. and Uchinuno, Y., 2007. Fatal winter dysentery with severe anemia in an adult cow, The Journal of Veterinary Medical Science, 69, 957-960 
Park, S.J., Jeong, C., Yoon, S.S., Choy, H.E., Saif, L.J., Park, S.H., Kim, Y.J., Jeong, J.H., Park, S.I., Kim, H.H., Lee, B.J., Cho, H.S., Kim, S.K., Kang, M.I. and Cho, K.O., 2006. Detection and characterization of bovine coronaviruses in fecal specimens of adult cattle with diarrhea during the warmer seasons, Journal of Clinical Microbiology, 44, 3178-3188

Reuter, G., Boldizsar, A. and Pankovics, P., 2009. Complete nucleotide and amino acid sequences and genetic organization of porcine kobuvirus, a member of a new species in the genus Kobuvirus, family Picornaviridae, Archives of Virology, 154, 101-108

Ribeiro, J., Lorenzetti, E., Alfieri, A.F. and Alfieri, A.A., 2014. Kobuvirus (Aichivirus B) infection in Brazilian cattle herds, Veterinary Research Communication, 38, 177-82

Stipp, D.T., Barry, A.F., Alfieri, A.F., Takiuchi, E., Amude, A.M. and Alfieri, A.A., 2009. Frequency of BCoV detection by a seminested PCR assay in faeces of calves from Brazilian cattle herds, Tropical Animal Health and Production, 41, 1563-1567
Takiuchi, E., Stipp, D.T., Alfieri, A.F. and Alfieri, A.A., 2006. Improved detection of bovine coronavirus $\mathrm{N}$ gene in faeces of calves infected naturally by a semi-nested PCR assay and an internal control, Journal of Virological Methods, 131, 148-154

Takiuchi, E., Barry, A.F., Alfieri, A.F., Filippsen, P. and Alfieri, A.A., 2009. An outbreak of winter dysentery caused by bovine coronavirus in a high-production dairy cattle herd from a tropical country, Brazilian Archives of Biology and Technology, 52, 57-61

Valle, M.B., Batista, E.R., Martell, B., Lepuroux, M.T.F. and Brandão, P., 2006. First report in Cuba of bovine coronavirus detection in a winter dysentery outbreak., Spanish Journal of Agricultural Research, 4, 221-224

Vilcek, S., Herring, A.J., Herring, J.A., Nettleton, P.F., Lowings, J.P. and Paton, D.J., 1994. Pestiviruses isolated from pigs, cattle and sheep can be allocated into at least three genogroups using polymerase chain reaction and restriction endonuclease analysis, Archives of Virology, 136, 309-323 